\title{
The effect of seed conditioning, short-term heat shock and salicylic, jasmonic acid or brasinolide on sunflower (Helianthus annuus $\mathrm{L}$.) chilling resistance and polysome formation
}

\author{
K. Górnik • A. Badowiec $\cdot$ S. Weidner
}

Received: 22 December 2013/Revised: 28 May 2014 / Accepted: 30 June 2014/Published online: 31 July 2014

(C) The Author(s) 2014. This article is published with open access at Springerlink.com

\begin{abstract}
The aim of this study was to develop the method for increasing resistance of sunflower seedlings 'Wielkopolski' to chilling. Seeds were conditioned at $25{ }^{\circ} \mathrm{C}$ for 2 days in water to 15,20 and $25 \%$ moisture content or in salicylic or jasmonic acid in concentration of $10^{-2} ; 10^{-3}$ and $10^{-4} \mathrm{M}$ or brassinolide in concentration of $10^{-6} ; 10^{-8}$ and $10^{-10}-15 \%$ moisture content. After 2 days of incubation the conditioned seeds were heat shocked at $45^{\circ} \mathrm{C}$ for $0,30,60,120$ and $240 \mathrm{~min}$ and $5 \mathrm{~mm}$ seedlings were exposed to chilling at $0{ }^{\circ} \mathrm{C}$ for 21 days. The effectiveness of the methods was assessed by evaluation of roots growth in Phytotoxkit Microbiotest, changes in the activity of dehydrogenases, the integrity of the cytoplasmic membrane and formation of polysomes after seedling were returned to $25{ }^{\circ} \mathrm{C}$ for $72 \mathrm{~h}$. Seeds were conditioned at $25{ }^{\circ} \mathrm{C}$ for 2 days in water to $15 \%$ moisture content and then heat shocked at $45^{\circ} \mathrm{C}$ for $2 \mathrm{~h}$ decreased chilling injury of seedlings expressed by subsequent growth of the roots, electrolyte leakage, dehydrogenases activity and polysomes formation. Application of heat shock of $45{ }^{\circ} \mathrm{C}$ for $2 \mathrm{~h}$ during seed conditioning additionally provided seedling protection against subsequent chilling conditions. Brasinolide, salicylic acid or jasmonic acid applied during seeds conditioning exhibited further beneficial effect on
\end{abstract}

Communicated by A. Gniazdowska-Piekarska.

K. Górnik ( $₫)$

Departament of Ornamental Nursery and Seed Science, Research Institute of Horticulture, Konstytucji 3 Maja 1/3, Skierniewice, Poland

e-mail: krzysztof.gornik@inhort.pl

A. Badowiec $\cdot$ S. Weidner

Department of Biochemistry Faculty of Biology, University of Warmia and Mazury in Olsztyn, Olsztyn, Poland seedling resistance to chilling. The most pronounced effect was obtained due to seed conditioning to $15 \%$ moisture content in solutions of brassinolide in concentration of $10^{-8}$ M. After 2 days of imbibition treated in this way seeds were exposed to heat shock at $45{ }^{\circ} \mathrm{C}$ for $2 \mathrm{~h}$. The role of physiological events in improvement of sunflower chilling tolerance are discussed.

Keywords Low - Temperature · Electrolyte leakage · Dehydrogenases activity - Salicylic acid · Jasmonic acid . Brasinolide

\section{Introduction}

Sunflower is one of the most important oil crops worldwide. It is mostly cultivated in the regions of high temperatures and long vegetation period. In Poland, the cultivation of sunflower grown for edible oil is strongly limited because they often maturate in conditions of low temperatures in autumn, dew in the mornings or evenings and high relative humidity. This hampers the natural drying of plants after ripening of achenes (Kluza-Wieloch 2003). Therefore, early sowing seems to be the way to avoid the critical period during autumn weather conditions. However, early sowing compared with conventional sowing is associated with long-term low temperature exposure during first stages of sunflower development. Such conditions can significantly inhibit seedlings emergence and plant growth as well as seriously cause plant chilling injury and infection by diseases (Bradlow 1990).

Such problems have increased the importance of sunflower tolerance to low temperatures. Many approaches have been tried to reduce chilling injury of growing plants (Mangrich and Saltveit 2000; Kang and Saltveit 2001; 
Saltveit 2001). These methods include: temperature conditioning, storage at high relative humidity or low pressure, application of specific chemical formulation, use of controlled atmospheres during chilling, increased atmospheric carbon dioxide levels, pre-treatments with calcium or ethylene, and conditioning near the chilling temperature before storage. More recently, the effects of exposure to elevated temperatures (i.e. temperature shock, heat shock or cold shock) have shown to induce tolerance to injury from low temperatures (Collins et al. 1993; Mangrich and Saltveit 2000; Kang and Saltveit 2001; Saltveit 2001). However, these methods were mainly used during the early growth of plants, which makes difficulties in applying them in practice during seed production. Therefore, it would be very useful if the positive effects of these methods could be applied during seed imbibition, before the radicles protrude the seed coat.

Salicylic acid, jasmonic acid and brassinolide are compounds naturally occurring in plants in very low amounts which are involved in plant responses to stress and take part in alleviating the negative effects of stress on plant (Korkmaz et al. 2005; Deef 2007; Bajguz and Hayat 2009; Gharib and Hegazi 2010). Besides, jasmonic and salicylic acid plays an important role in seedlings immunity to pathogens. However, little is known about its effect in combination with short-term high temperature applied during seed imbibition on seedlings resistance to chilling.

Due to a lack of information on the subject, the aim of the present study was to evaluate the effect of short-term heat shock applied during seed conditioning in water or in the presence of salicylic acid, jasmonic acid or brassinolide on improvement of plant tolerance to negative effects of chilling. In order to achieve this aim, the growth of roots, activity of dehydrogenases, the integrity of the cytoplasmic membrane and formation of polysomes were examined.

\section{Materials and methods}

Plant material

Seeds of sunflower (Helianthus annuus subsp. sativus) "Wielkopolski" were purchased from HR Strzelce Sp. Z o.o. company (Borowo, Poland). Seeds until the start of experiments were held at $15{ }^{\circ} \mathrm{C}$ and $30 \%$ of relative humidity.

Seeds conditioning, heat shock treatments and measurements of root length

Seeds were soaked in limited amounts of water to 15,20 and $25 \%$ moisture content at $25{ }^{\circ} \mathrm{C}$ and incubated for 2 days in air-tight glass bottles at the same temperature.
During the incubation, the seeds were aired (ventilated) every day for about $15 \mathrm{~s}$. After 2 days of incubation the conditioned seeds were subjected to high temperature (heat shock) of $45{ }^{\circ} \mathrm{C}$ for $0,30,60,120$ and $240 \mathrm{~min}$ and transferred to $6 \mathrm{~cm}$ Petri dishes at $25{ }^{\circ} \mathrm{C}$. The germinated seeds with $5 \mathrm{~mm}$ root in length were moved to Phytotoxkit Microbiotest (Persoone and Vangheluwe 2000). Afterwards, the seedlings were chilled at $0{ }^{\circ} \mathrm{C}$ for 21 days. Root length was determined after seedlings were returned to $25{ }^{\circ} \mathrm{C}$ for $72 \mathrm{~h}$.

In the next experiments the seeds were conditioned to $15 \%$ moisture content either in water or in solutions of salicylic or jasmonic acid in concentration of $10^{-2} ; 10^{-3}$ and $10^{-4} \mathrm{M}$ or brassinolide in concentration of $10^{-6} 10^{-8}$ and $10^{-10} \mathrm{M}$. After 2 days of incubation the conditioned seeds were heat shocked at $45{ }^{\circ} \mathrm{C}$ for $2 \mathrm{~h}$ and transferred to Petri dishes at $25^{\circ} \mathrm{C}$ for further germination. These conditions were experimentally selected on the basis of first experiment as the most beneficial condition for induction of seedling resistance to chilling. The seedlings with $5 \mathrm{~mm}$ length were transferred to Phytotoxkit Microbiotest, chilled at $0{ }^{\circ} \mathrm{C}$ for 21 days and then electrolyte leakage, dehydrogenases activity and polysomes formation were evaluated. After seedlings were returned to $25^{\circ} \mathrm{C}$ for $72 \mathrm{~h}$, the root length was determined.

\section{Measurement of electrolyte leakage}

The conditioned, heat shocked seeds and then chilled seedlings were subjected to electrolyte leakage assessments. Twenty-five seedlings, in four replications were soaked in $5 \mathrm{ml}$ of distilled water. The electrolyte leakage was measured after $4 \mathrm{~h}$ of incubation at $20{ }^{\circ} \mathrm{C}$. Results correspond to the means of four measurements. A microcomputer conductivity meter CC-551 (ELMETRON, Poland) was used to measure the electrical conductivities (in $\mu \mathrm{S}$ ) of the leaches of seedlings (Górnik and Grzesik 2002).

\section{Dehydrogenases activity}

Dehydrogenases activity were determined in the present study as the frequent, reliable and good marker for scoring seed vigor classes. The method used for measuring the activity of dehydrogenases is based on the fact that 2,3,5triphenyl tetrazolium chloride (TTC) interacts with the reduction processes of living cells and accepts hydrogen from dehydrogenases. By hydration of the TTC a red, stable and non-diffusible substance, triphenyl formazan is produced in living cells (Pandey 1989). $0.2 \mathrm{~g}$ of isolated from seedlings roots were placed in Eppendorf tubes, ground and incubated in $1 \mathrm{ml}$ of $0.1 \mathrm{M}$ sodium phosphate buffer, pH 7.2 containing $0.7 \%$ (w/v) of TTC at $25{ }^{\circ} \mathrm{C}$ for 
$24 \mathrm{~h}$. After that time samples were centrifuged (5 min; $5,000 \times g$ ) and the pellet was extracted six times with $1 \mathrm{ml}$ of acetone. The solution absorbance was measured at $488 \mathrm{~nm}$. A standard curve was prepared from known concentration of formazan. Each determination was made four times.

\section{Polysome evaluation}

Frozen seedlings in amount of $0.5 \mathrm{~g}$ were ground under liquid nitrogen using cooled mortar and pestle and suspended in about $3 \mathrm{ml}$ of buffer $\mathrm{U}$ containing $2 \%$ PTE (polyoxyethylene-10-tridecyl ether, a non-ionic detergent); $1 \%$ DOC (sodium deoxycholate); $200 \mathrm{mM}$ Tris$\mathrm{HCl}, \mathrm{pH} 8.5 ; 50 \mathrm{mM}$ potassium acetate; $25 \mathrm{mM}$ magnesium acetate; $2 \mathrm{mM}$ EGTA; $100 \mathrm{mg} / \mathrm{ml}$ heparin and centrifuged at $12,000 \times g$ for $20 \mathrm{~min}$ (Abe et al. 1992). The obtained supernatants, containing total extractable fraction of polyribosomes, were placed in the centrifuge tubes, on top of $0.5 \mathrm{ml}$ of $50 \%$ "sucrose cushion". Polysomes were purified and enriched by pelleting through the sucrose cushions at $330,000 \times g$ for $90 \mathrm{~min}$ (SW $55 \mathrm{Ti}$ rotor, Beckman). Pellets were then resuspended in $0.5 \mathrm{ml}$ of buffer $\mathrm{U}$ and centrifuged for $5 \mathrm{~min}$ at $12,000 \times g$. The quantity of the ribosomes was estimated by measuring the absorbance at $260 \mathrm{~nm}$, according to the method developed by Gualerzi and Cammarano (1969), which assumed that the absorbance of $1 \%$ solution of ribosomes in a cuvette with a $1 \mathrm{~cm}$ optical path equals 13.5. In order to separate the individual components of the extract (ribosomal subunits, monosomes and polysomes), $200 \mu \mathrm{l}$ of the aliquot was placed on top of a 15-60\% density gradient of sucrose dissolved in buffer B $(50 \mathrm{mM}$ Tris- $\mathrm{HCl}, \mathrm{pH} 8.5 ; 20 \mathrm{mM}$ potassium acetate; $10 \mathrm{mM}$ magnesium acetate) and centrifuged at $330,000 \times g$ for $30 \mathrm{~min}$. The ribosome profiles were monitored by measuring the absorbance at $254 \mathrm{~nm}$ using a UA-5 flow recorder (ISCO, Lincoln, NE, USA) according to Davies and Abe (1995). The percentage of polysomes was determined by calculating the area under the polysome peaks in relation to the total ribosomal profile after subtracting the blank gradient baseline. All steps were carried at $0-4{ }^{\circ} \mathrm{C}$.

\section{Statistical analyses}

The experiment was conducted three times. The measurements of root length was designed in four replications, each comprising ten seedlings. Electrolyte leakage, dehydrogenases activity and polysomes formation were repeated four times. The differences between the means were estimated by the Duncan multiple range test at a significance level of $P=0.05$.

\section{Results and discussion}

The former experiments showed that sunflower seedlings are sensitive to an exposure of chilling temperatures (Górnik 2011). The chilling sensitivity of the seedlings was observed as root damages expressed by external discoloration and inhibition of roots growth. Similarly, in the present study sunflower sensitivity to chilling among others was investigated by roots growth in Phytotoxkit Microbiotest. The measurements of root elongation after chilling are considered as one of the best indicators for the evaluation of chilling injury severity (Jennings and Saltveit 1994; Mangrich and Saltveit 2000; Saltveit 2001; Kang and Saltveit 2001; Górnik 2011).

Seeds conditioned in limited water supply significantly decreased chilling injury of seedlings expressed by subsequent growth of the roots (Table 1). Similarly, soybean seed priming increased their tolerance to chilling temperature (Farooq et al. 2008; Posmyk et al. 1999, 2001). The lower seed moisture content was the more pronounced, effect of seed conditioning on seedling resistance to chilling was observed (Table 1). The best effect was obtained when seeds were conditioned to $15 \%$ moisture content. Application of heat shock $\left(45^{\circ} \mathrm{C}\right)$ additionally affected seedling resistance to chilling. However, the extent of the profitable impact depended on the duration of $45{ }^{\circ} \mathrm{C}$ exposure during seed imbibition. The most beneficial result was obtained when seeds after 2 days of imbibition were heat shocked at $45{ }^{\circ} \mathrm{C}$ for $2 \mathrm{~h}$, which was previously examined (data not shown). After that treatment the roots of these seedlings were more than twice longer as the control ones. Similarly, Jennings and Saltveit (1994) reported positive response of high temperature for inducing chilling tolerance in cucumber.

Table 1 Root length $(\mathrm{cm})$ of Wielkopolski sunflower seedling after seed conditioning and heat shock application

\begin{tabular}{llll}
\hline Seed treatments & \multicolumn{3}{l}{ Seed moisture content $(\%)$} \\
\cline { 2 - 4 } & 15 & 20 & 25 \\
\hline Control (seed imbibed of filter paper) & $23.6 \mathrm{a}$ a & $23.6 \mathrm{a}$ & $23.6 \mathrm{a}$ \\
Conditioning (0 min at $\left.45^{\circ} \mathrm{C}\right)$ & $32.9 \mathrm{~b}$ & $27.5 \mathrm{~b}$ & $25.2 \mathrm{~b}$ \\
Conditioning $\left(30 \mathrm{~min}\right.$ at $\left.45^{\circ} \mathrm{C}\right)$ & $47.0 \mathrm{c}$ & $43.4 \mathrm{c}$ & $34.8 \mathrm{c}$ \\
Conditioning $\left(60 \mathrm{~min}\right.$ at $\left.45^{\circ} \mathrm{C}\right)$ & $51.3 \mathrm{~cd}$ & $39.6 \mathrm{bc}$ & $30.1 \mathrm{bc}$ \\
Conditioning $\left(120 \mathrm{~min}\right.$ at $\left.45^{\circ} \mathrm{C}\right)$ & $52.3 \mathrm{~d}$ & $38.4 \mathrm{bc}$ & $27.7 \mathrm{bc}$ \\
Conditioning $\left(240 \mathrm{~min}\right.$ at $\left.45^{\circ} \mathrm{C}\right)$ & $40.9 \mathrm{bc}$ & $37.6 \mathrm{bc}$ & $25.7 \mathrm{~b}$ \\
\hline
\end{tabular}

Seeds were conditioned at $25{ }^{\circ} \mathrm{C}$ for $16 \mathrm{~h}$ to $15,20,25 \%$ moisture content, imbibed for $2 \mathrm{~h}$ and then heat shocked for $0,30,60,120$, $240 \mathrm{~min}$ and returned to $25^{\circ} \mathrm{C}$ for further germination. Seedlings with $5 \mathrm{~mm}$ length were chilled at $0{ }^{\circ} \mathrm{C}$ for 21 days. Root length was determined after seedlings were returned to $25^{\circ} \mathrm{C}$ for $72 \mathrm{~h}$

${ }^{a}$ Means within columns with the same letter are not significantly different at $5 \%$ according to Duncans's multiple range test 

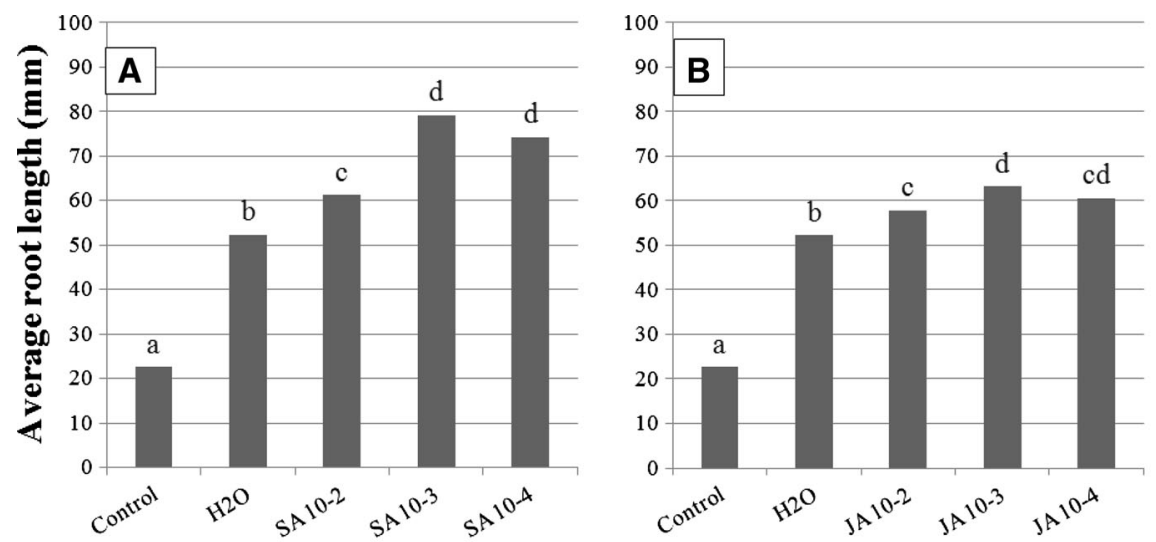

\section{Treatments}

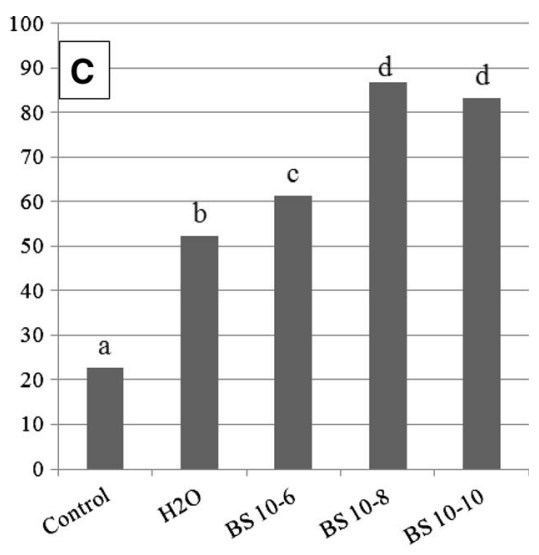

Fig. 1 Root growth of Wielkopolski sunflower seedlings after seed conditioning in water or solutions of a salicylic acid (SA) in concentration of $10^{-2} ; 10^{-3}$ and $10^{-4} \mathrm{M}$ or $\mathbf{b}$ jasmonic acid (JA) in concentration of $10^{-2} ; 10^{-3}$ and $10^{-4} \mathrm{M}$ or $\mathbf{c}$ brassinolide (BS) in concentration of $10^{-6} ; 10^{-8}$ and $10^{-10} \mathrm{M}$ to $15 \%$ moisture content.

Salicylic acid, jasmonic acid or brassinolide applied during seed conditioning together with heat shock treatment additionally provided seedling protection against subsequent chilling condition (Fig. 1). The most resistant seedlings to low temperature influence were obtained when seeds were conditioned in the solution of $10^{-8}$ or $10^{-10} \mathrm{M}$ of brassinolide. After transferring them to $25{ }^{\circ} \mathrm{C}$ for $72 \mathrm{~h}$ their roots were four times longer than the control ones. Similarly, leaves spraying with brassinolide on the rice seedlings increased plant height and the fresh weights of tops and roots under chilling stress (Bajguz and Hayat 2009). Furthermore, it has been reported that brassinolide improve seed germination and seedling growth of maize (Zea mays) (He et al. 1991) and cucumber (Cucumis sati$v u s$ ) (Khripach et al. 1999) under chilling stress. It also takes part in the regulation of growth, development and photosynthesis of plants (Bajguz 2010; Bajguz and Czerpak 1998).

In the present study, similar effects to brassinolide were observed after application of salicylic acid in concentration of $10^{-3}$ and $10^{-4} \mathrm{M}$ (Fig. 1). It is also well documented that exogenous salicylic acid generated resistance towards chilling or cold stress in maize plants, grown in hydroponic solutions, supplemented with $0.5 \mathrm{mM}$ of salicylic acid (Janda et al. 1999). In other research salicylic acid enhanced the germination percentage of carrot seeds (Rajasekaran et al. 2002). Shakirowa et al. (2003) reported that salicylic acid caused accumulation of abscisic acid (ABA) which might contribute to a preadaptation of plants to stress, since $\mathrm{ABA}$ in known to have a key role in the induction of the synthesis of stress protein. Salicylic acid also caused a significant increase in the concentration of proline in wheat seedling. Shakirowa et al. (2003)
The seeds conditioned at $25^{\circ} \mathrm{C}$ for 2 days were heat shocked for $120 \mathrm{~min}$ and returned to $25^{\circ} \mathrm{C}$ for further germination. Seedlings with $5 \mathrm{~mm}$ length were chilled for 21 days at $0{ }^{\circ} \mathrm{C}$. Root length was determined after seedlings were returned from chilling condition to $25{ }^{\circ} \mathrm{C}$ for $72 \mathrm{~h}$

demonstrated that proline is implicated in the mechanism of action of SA in wheat plants, achieved through its influence on the accumulation of ABA. The present study also clearly demonstrated that sunflower after seed conditioning in jasmonic acid solution exhibited higher resistance to chilling condition compared to that of the control (Fig. 1). Due to such treatments the length of roots increased over twice longer than the control. Korkmaz et al. (2005) also found that the inclusion of jasmonic acid into the priming solution improved low temperature performance of muskmelon seeds and led to the higher emergence percentages.

Posmyk et al. (2001) reported that measurements of electrolyte leakage in the soybean embryonic axis is a good indication of chilling tolerance. It was established that the rate of iron leakage was highly correlated with the degree of chilling injury (Saltveit 1989). Leakage of solutes from chilled imbibing seeds suggests that membrane re-organization is impaired at low temperatures (Bramlage et al. 1978). In the present experiment, conditioning of seeds in water and subjecting them to short-term heat shock resulted in a decreased electrolyte leakage to the medium compared to the control (Fig. 2). Presumably, short-term exposure to high temperature initiates an adaptive mechanism in membranes for further detrimental effects of chilling. Similarly, the soybean seed priming protected membranes integrity from chilling damages (Posmyk et al. 2001). The obtained results revealed that conditioning of seeds in solutions of salicylic acid, jasmonic acid or brassinolide additionally decreased their electrolyte leakage indicating improved seedling resistance to chilling. The most pronounced effect was obtained due to seeds conditioning in $10^{-8}$ or $10^{-10} \mathrm{M}$ of brassinolide to $15 \%$ moisture content and then subjecting 


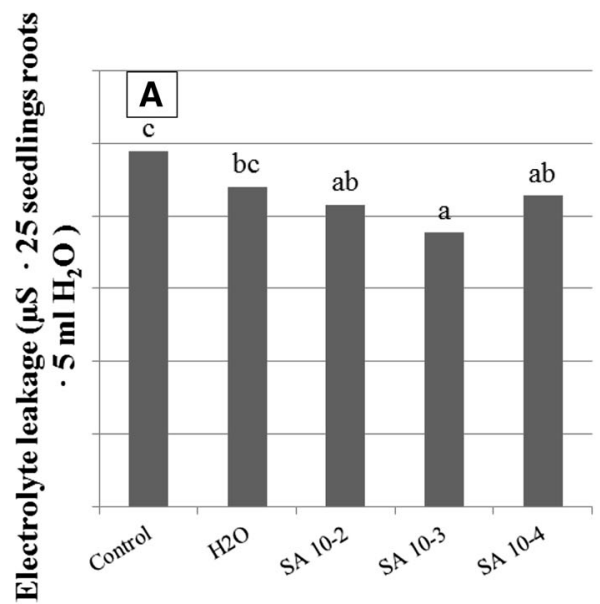

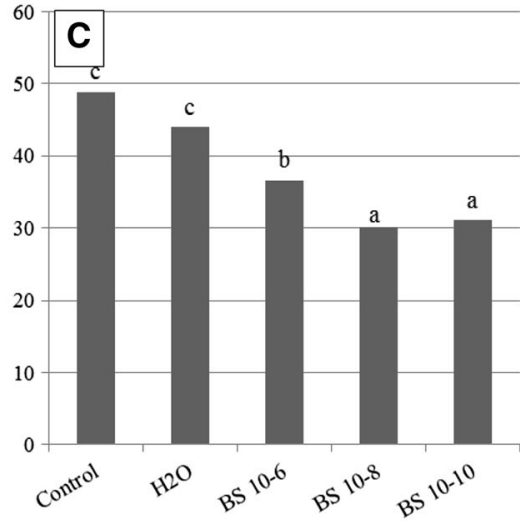

Fig. 2 Electrolyte leakage of sunflower seedlings obtained from seeds conditioned in water or solutions of a salicylic acid (SA) in concentration of $10^{-2} ; 10^{-3}$ and $10^{-4} \mathrm{M}$ or $\mathbf{b}$ jasmonic acid (JA) in concentration of $10^{-2} ; 10^{-3}$ and $10^{-4} \mathrm{M}$ or $\mathbf{c}$ brassinolide (BS) in concentration of $10^{-6} ; 10^{-8}$ and $10^{-10} \mathrm{M}$ to $15 \%$ moisture content. The seeds conditioned at $25^{\circ} \mathrm{C}$ for 2 days were heat shocked for $120 \mathrm{~min}$ and returned to $25^{\circ} \mathrm{C}$ for further germination. Seedlings with $5 \mathrm{~mm}$ length were chilled for 21 days at $0{ }^{\circ} \mathrm{C}$
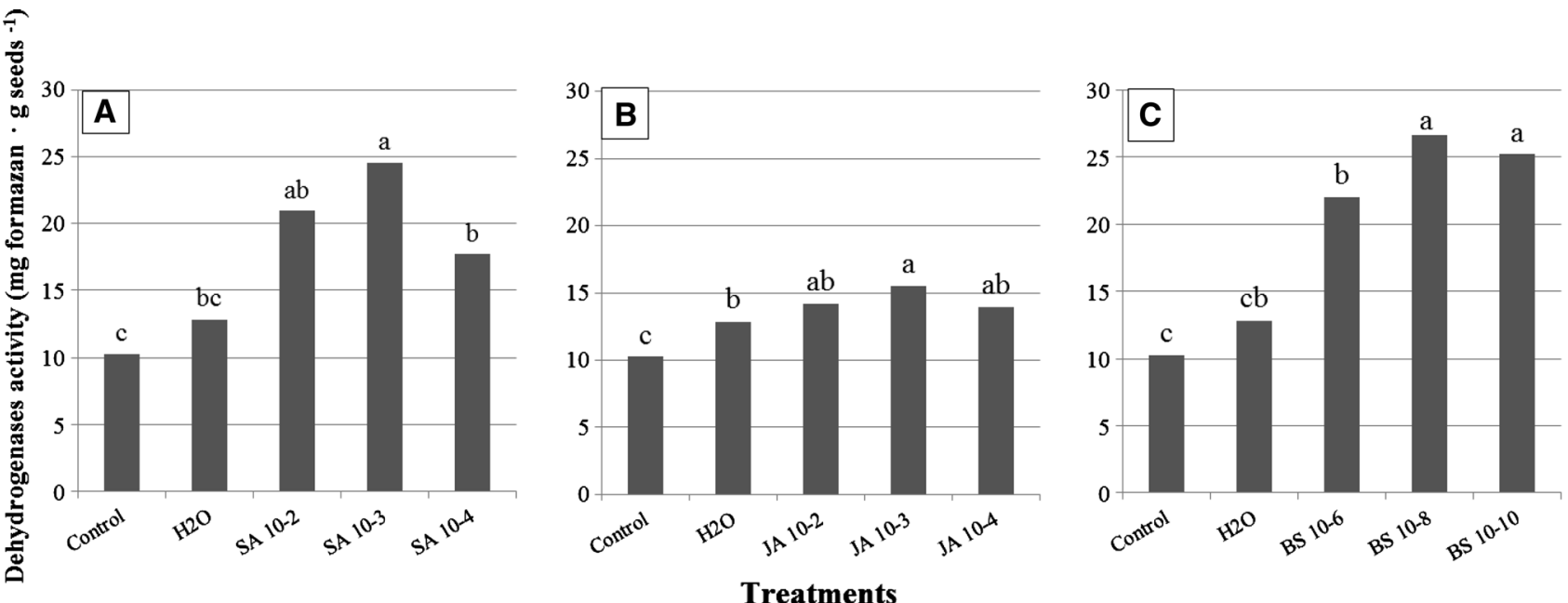

Fig. 3 Dehydrogenases activity of sunflower seedlings roots obtained from seeds conditioned in water or solutions of a salicylic acid (SA) in concentration of $10^{-2} ; 10^{-3}$ and $10^{-4} \mathrm{M}$ or $\mathbf{b}$ jasmonic acid (JA) in concentration of $10^{-2} ; 10^{-3}$ and $10^{-4} \mathrm{M}$ or $\mathbf{c}$ brassinolide (BS) in

them to heat shock at $45{ }^{\circ} \mathrm{C}$ for $2 \mathrm{~h}$. Apparently, membranes integrity were protected from chilling damages due to seeds conditioning in this phytohormone and then heat shocked. In maize experiment the electrolyte leakage was less pronounced in plants pretreated with salicylic acid than in those which were not supplied with this plant growth regulator (Janda et al. 1999). Protective effects of this compound on membranes against chilling may have one of the mechanisms in coping with that stress.

Heat shock treatment during seed conditioning in water positively affected dehydrogenases activity (Fig. 3). Addition of salicylic acid, jasmonic acid or brassinolide concentration of $10^{-6} ; 10^{-8}$ and $10^{-10} \mathrm{M}$ to $15 \%$ moisture content. The seeds conditioned at $25^{\circ} \mathrm{C}$ for 2 days were heat shocked for $120 \mathrm{~min}$ and returned to $25^{\circ} \mathrm{C}$ for further germination. Seedlings with $5 \mathrm{~mm}$ length were chilled for 21 days at $0{ }^{\circ} \mathrm{C}$

during seed conditioning affected dehydrogenases activity in a greater extent. The greatest total activity of these enzymes was observed when seeds were conditioned for 2 days in $10^{-8}$ or $10^{-10} \mathrm{M}$ of brassinolide to $15 \%$ moisture content and then exposed to heat shock of $45^{\circ} \mathrm{C}$ for $2 \mathrm{~h}$. Activity of dehydrogenases (respiratory enzymes) is considered as an index of tissue respiration and metabolism (Kasai et al. 1998; Białecka and Kępczyński 2010; Farooq et al. 2010). Presumably, an increase of the respiration rate due to brassinolide application improved sunflower chilling tolerance. An increase of the respiration rate was suggested as an adaptive strategy for stress in Triticum aestivum seeds 
Control
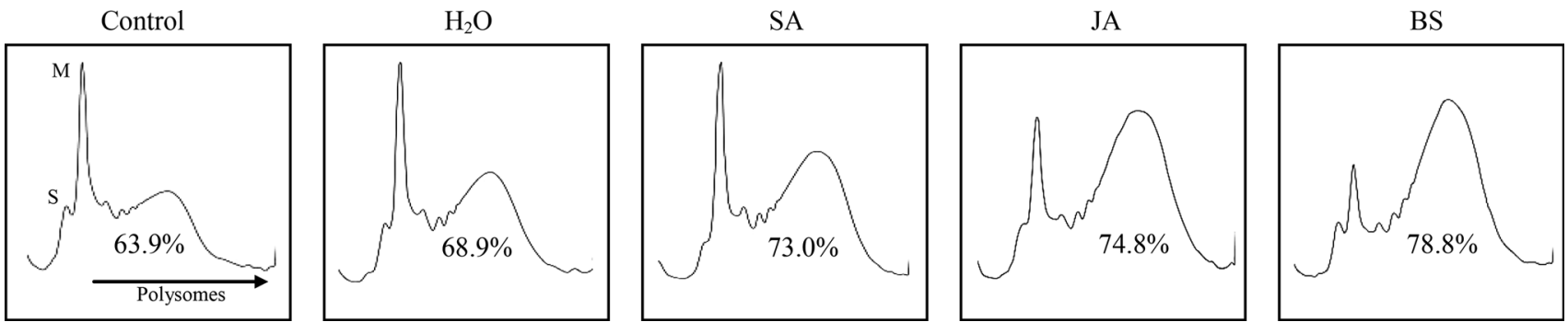

Fig. 4 The sucrose-gradient sedimentation profiles and the percentage of polysomes in the total ribosomal fractions of sunflower seedlings obtained from seeds conditioned in water or solutions of a salicylic acid (SA) in concentration of $10^{-2} ; 10^{-3}$ and $10^{-4} \mathrm{M}$ or b jasmonic acid (JA) in concentration of $10^{-2} ; 10^{-3}$ and $10^{-4} \mathrm{M}$ or c brassinolide (BS) in concentration of $10^{-6} ; 10^{-8}$ and $10^{-10} \mathrm{M}$ to $15 \%$ moisture content. The seeds conditioned at $25^{\circ} \mathrm{C}$ for 2 days were heat shocked for $120 \mathrm{~min}$ and returned to $25^{\circ} \mathrm{C}$ for further germination. Seedlings with $5 \mathrm{~mm}$ length were chilled for 21 days at $0{ }^{\circ} \mathrm{C}$. S-ribosome subunits, M-monosomes germinating under salinity (Kasai et al. 1998). Similarly, both salicylic or jasmonic acid in all examined concentrations stimulated dehydrogenases activity suggesting that these compounds naturally occurring in plants promoted respiratory enzyme activity leading to increased resistance of sunflower seedling to chilling conditions.

Reprogramming of gene expression is essential for the effective plant response to stress but the control at the level of protein translation allows more immediate response to adverse conditions by changing the intensity of stress proteins production without time- and energy-consuming phase of transcription (Branco-Price et al. 2008). The assembly of numerous ribosomes on one mRNA template enables to increase efficiency of translation and accelerate protein synthesis. It is believed that increased rate of polysomes formation reflects higher translational activity in cell (Noll 2008). Many abiotic stresses, such as water deficit, heat and oxygen stress, inhibit the formation of polysomes in plants (Kawaguchi et al. 2004; Kosowska et al. 2004; Swaminathan et al. 2006; Branco-Price et al. 2008) which is often associated with the inhibition of plant growth. The reduction of global protein synthesis under unfavorable conditions may depend both on the duration and strength of the stress (Kosowska et al. 2004; Yángüez et al. 2013).

In this work, after 2 days of imbibition, the pre-conditioned seeds were exposed to heat shock at $45^{\circ} \mathrm{C}$ for $2 \mathrm{~h}$. The increase in ribosomes content and contribution of polysomes in the total ribosomal fractions (Fig. 4) observed in response to salicylic acid, jasmonic acid and brassinolide suggest the enhancement of translational activity in the given circumstances in comparison to the non-conditioned seedlings. The most pronounced result was obtained after seed conditioning in the solution of brassinolide in concentration of $10^{-8} \mathrm{M}$. Both the ribosome content and the percentage of ribosomes incorporated into polysomes were the highest in the given conditions. Such a result is not surprising as this phytohormone which is known to be an important regulator of transcription and translation (Dhaubhadel et al. 2002). There is evidence that brassinosteroids help to remodel the translation initiation step during heat shock (Dhaubhadel et al. 2002). It was proved that addition of brassinosteroids improves plant thermotolerance by a positive effect on the polysomerelated heat-mediated translation efficiency in Brassica napus and tomato seedlings (Dhaubhadel et al. 1999, 2002). The increased polysome content in response to brassinolide may indicate stimulation of the synthesis of proteins involved in alleviating the negative effects of stress, such as enzymatic antioxidants (Hayat and Ahmad 2003; Fariduddin et al. 2005) or heat shock proteins (Dhaubhadel et al. 2002). It can be assumed that maintaining higher translational capacity during stress after brassinolide addition might be one of the reasons of higher seedling's tolerance to stress observed in this work.

The presented date indicated that seed conditioning in water and application of short-term heat shocks can induce substantial tolerance to subsequent chilling of young sunflower seedlings. Presumably, such treatments may have protective effects on membranes and could induce synthesis of heat shock proteins which reduced chilling injury. Application especially of brasinolide during seeds conditioning promoted protective reaction, which decreased injurious effects of chilling. It could be caused by stimulation of the synthesis of proteins such as enzymatic antioxidants which may have one of the mechanisms in coping with that stress. While salicylic acid could accumulate abscisic acid (ABA) and proline which might contribute to a preadaptation of plants to stress. Further research is needed to investigate the exact mechanism of these compounds in an achievement of chilling tolerance of sunflower seedling.

Author contribution Krzysztof Górnik prepared experimental design, carried out most of the research and was the main author of this manuscript. Anna Badowiec conducted experiments concerning ribosomal fractions content, sucrose-gradient sedimentation profiles, 
the percentage of polysomes in the total ribosomal fractions and helped with manuscript preparation. Stanisław Weidner proposed conception of the study concerning polysomes, discussed the results and commented on the manuscript.

Open Access This article is distributed under the terms of the Creative Commons Attribution License which permits any use, distribution, and reproduction in any medium, provided the original author(s) and the source are credited.

\section{References}

Abe S, Ito Y, Davies E (1992) Co-sedimentation of actin, tubulin and membranes in the cytoskeleton fractions from peas and mouse 3T3 cells. J Exp Bot 43:941-949

Bajguz A (2010) An enhancing effect of exogenous brassinolide on the growth and antioxidant activity in Chlorella vulgaris cultures under heavy metals stress. Environ Exp Bot 68:175-179

Bajguz A, Czerpak R (1998) Physiological and biochemical role of brassinosteroids and their structure-activity relationship in the green alga Chlorella vulgaris Beijerinck (Chlorophyceae). J Plant Growth Regul 17:131-139

Bajguz A, Hayat S (2009) Effects of brassinosteroids on the plant responses to environmental stresses. Plant Physiol Biochem $47: 1-8$

Białecka B, Kępczyński J (2010) Germination, $\alpha$-, $\beta$-amylase and total dehydrogenase activities of Amaranthus caudatus seeds under water stress In the presence of ethephon or gibberellin $\mathrm{A}_{3}$. Acta Biol Cracov Ser Bot 52:7-12

Bradlow J (1990) Chilling sensitivity of photosynthetic oil-seedlings. I cotton and sunflower. J Exp Bot 41:1585-1593

Bramlage WJ, Leopold AC, Parrish DT (1978) Chilling stress to soybeans during imbibition. Plant Physiol 61:525-529

Branco-Price C, Kaiser A, Jang CJH, Larive CK, Bailey-Serres J (2008) Selective mRNA translation coordinates energetic and metabolic adjustments to cellular oxygen deprivation and reoxygenation in Arabidopsis thaliana. Plant J 56:743-755

Collins GG, Nie X, Saltveit ME (1993) Heat-shock increases chilling tolerance of mung bean hypocotyl tissue. Physiol Plant 89:117-124

Davies E, Abe S (1995) Methods for isolation and analysis of polyribosomes. In: Galbraith DW, Bourque DP, Bohnert HJ (eds) Methods in cell biology. Methods in plant cell biology. Academic Press, New York, pp 209-222

Deef HE (2007) Influence of salicylic acid on stress tolerance during seed germination of Triticum aestivum and Hordeum vulgare. Adv Biol Res 1(1-2):40-48

Dhaubhadel S, Chaudhary S, Dobinson KF, Krishna P (1999) Treatment with 24-epibrassinolide, a brassinosteroid, increases the basic thermotolerance of Brassica napus and tomato seedlings. Plant Mol Biol 40:333-342

Dhaubhadel S, Browning KS, Gallie DR, Krishna P (2002) Brassinosteroid functions to protect the translational machinery and heat-shock protein synthesis following thermal stress. Plant J 29:681-691

Fariduddin Q, Hayat S, Ali B, Ahmad A (2005) Effect of 28-homobrassinolide on the growth and yield of Vigna radiata. Ann Biol $21: 1-6$

Farooq M, Basra SMA, Rehman H, Saleem BA (2008) Seed priming enhances the performance of late sown wheat (Triticum aestivum L.) by improving chilling tolerance. J Agron Crop Sci 194:55-60

Farooq M, Wahid A, Ahmad N, Asad SA (2010) Comparative efficacy of surface drying and re-drying seed priming in rice: changes in emergence, seedling growth and associated metabolic events. Paddy Water Environ 8:15-22
Gharib FA, Hegazi AZ (2010) Salicylic acid ameliorates germination, seedling growth, phytohormone and enzymes activity in bean (Phaseolus vulgaris L.) under cold stress. J Am Sci 6:675-683

Górnik K (2011) The effect of temperature treatments during 'Wielkopolski' sunflower seed imbibition and storage on plant tolerance to chilling. Folia Hortic 23:83-88

Górnik K, Grzesik M (2002) Effect of Asahi SL on China aster "Aleksandra" sees yield, germination and same metabolic events. Acta Physiol Plant 24:379-383

Gualerzi C, Cammarano P (1969) Comparative electrophoretic studies on the protein of chloroplast and cytoplasmic ribosomes of spinach leaves. Biochim Biophys Acta 190:170-186

Hayat S, Ahmad A (2003) Soaking-seeds of Lens culinaris with 28-homobrassinolide increased nitrate reductase activity and grain yield in the field in India. Ann Appl Biol 143:121-124

He RY, Wang GJ, Wang XS (1991) Effect of brassinolide on growth and chilling resistance of maize seedlings. In: Cutler HG, Yokota $\mathrm{T}$, Adam G (eds) Brassinosteroids: chemistry, bioactivity and applications. American Chemical Society, Washington, pp 220-230

Janda T, Szalai G, Tari I, Paldi E (1999) Hydroponic treatment with salicylic acid decreases the effects of Schilling injury in maize (Zea mays L.) plants. Planta 208:175-180

Jennings P, Saltveit ME (1994) Temperature effects on imbibition and germination of cucumber (Cucumis sativus) seeds. J Am Soc Hortic Sci 119:464-467

Kang H, Saltveit ME (2001) Activity of enzymatic antioxidant defense systems in chilled and heat shocked cucumber seedling radicals. Physiol Plant 113:548-556

Kasai K, Mori N, Nakamura C (1998) Changes in the respiratory pathways during germination and early seedling growth of common wheat under normal and $\mathrm{NaCl}$ stressed conditions. Cereal Res Comm 26:217-224

Kawaguchi R, Girke T, Bray EA, Bailey-Serres J (2004) Differential mRNA translation contributes to gene regulation under nonstress and dehydration stress conditions in Arabidopsis thaliana. Plant J 38:823-839

Khripach VA, Zhabinskii VN, Groot AE (1999) Brassinosteroids: a new class of plant hormones. Academic Press, San Diego

Kluza-Wieloch M (2003) Plant height at different developmental stages in observed types of sunflower (Hellianthus annus L.) cultivars. Rocz AR Pozn 6:93-105

Korkmaz A, Ozbay N, Tiryaki I, Nas MN (2005) Combining priming and plant growth regulators improves muskmelon germination and emergence at low temperatures. Eur J Hortic Sci 70:29-34

Kosowska M, Frączek E, Amarowicz R, Karamać M, Abe S, Weidner S (2004) Water-deficit-induced changes in cytoskeleton-bound and other polysomal populations in embryonic tissue during triticale caryopsis germination. Acta Physiol Plant 26:67-74

Mangrich ME, Saltveit ME (2000) Effect of chilling, heat shock, and vigour on the growth of cucumber (Cucumis sativus) radicles. Physiol Plant 109:137-142

Noll H (2008) The discovery of polyribosomes. BioEssays 30:1220-1234

Pandey DK (1989) Ageing of French bean seeds at ambient temperature in relation to vigour and viability. Seed Sci Technol $17: 41-47$

Persoone G, Vangheluwe ML (2000) Toxicity determination of the sediments of the river Seine in France by application of a battery of microbiotests. In: Persoone G, Janssen C, De Coen W (eds) New Microbiotests for Routine Toxicity Screening and Biomonitoring. Kluwer Academic, New York, pp 427-439

Posmyk M, Corbineau F, Vinel D, Come D (1999) Effects of priming on physiological and metabolic events induced by chilling in soybean (Glycine max (L.) Merr.) seeds. Zeszyty Problemowe Postępów Nauk Rolniczych 469:117-125 
Posmyk MM, Corbineau F, Vinel D, Bailly C, Come D (2001) Osmoconditioning reduces physiological and biochemical damage induced by chilling in soybean seeds. Physiol Plant 111:473-482

Rajasekaran LR, Stiles A, Caldwell CD (2002) Stand establishment in processing carrot-effects of various temperature regimes on germination and the role of salicylates in promoting germination at low temperatures. Can J Plant Sci 82:443-450

Saltveit ME (1989) A kinetic examination of iron leakage from chilled tomato pericarp discs. Acta Hortic 258:617-622

Saltveit ME (2001) Chilling injury is reduced in cucumber and rice seedlings and in tomato pericarp discs by heat-shocks applied after chilling. Postharvest Biol Technol 21:169-177
Shakirowa FM, Sakhabutdinova AR, Bezrukova MV, Fatkhutdinova RA, Fatkhutdinova DR (2003) Changes in the hormonal status of wheat seedlings induced by salicylic acid and salinity. Plant Sci 164:317-322

Swaminathan S, Masek T, Molin C, Pospisek M, Sunnerhagen P (2006) Rck2 is required for reprogramming of ribosomes during oxidative stress. Mol Biol Cell 17:1472-1482

Yángüez E, Castro-San AB, Fernandez-Bautista N, Oliveros JC, Castellano MM (2013) Analysis of genome-wide changes in the translatome of Arabidopsis seedlings subjected to heat stress. PLoS One 8:e71425 